\title{
Trocas Gasosas do Feijao-Caupi Cultivado no Nordeste Paraense em Resposta à Deficiência Hídrica Forçada Durante a Fase Reprodutiva
}

\author{
Paulo Jorge de Oliveira Ponte de Souza ${ }^{1,2}$ (D), Denilson Pontes Ferreira ${ }^{2}$, Denis de Pinho Sousa ${ }^{2}$, \\ Hildo Giuseppe Garcia Caldas Nunes ${ }^{2}$, Antônio Vinicius Correa Barbosa ${ }^{3}$ \\ ${ }^{1}$ Instituto Socioambiental e dos Recursos Hídricos, Universidade Federal Rural da Amazônia, \\ Belém, PA, Brasil. \\ ${ }^{2}$ Programa de Pós-Graduação em Agronomia, Universidade Federal Rural da Amazônia, Belém, \\ $P A$, Brasil. \\ ${ }^{3}$ Instituto Ciberespacial, Universidade Federal Rural da Amazônia, Belém, PA, Brasil.
}

Recebido em: 28 de Dezembro de 2018 - Aceito em: 11 de Janeiro de 2019

\begin{abstract}
Resumo
O feijão-caupi é uma leguminosa bastante cultivada no Norte e Nordeste do Brasil, mas no Pará, a cultura apresenta baixa produtividade, devido à baixa fertilidade dos solos e especialmente à deficiência hídrica. $\mathrm{O}$ trabalho teve como objetivo avaliar o efeito de distintos níveis de deficiência hídrica acumulada durante a fase reprodutiva nas trocas gasosas do feijão-caupi. O experimento foi conduzido em Castanhal-Pa, em 2015 e 2016, em um delineamento de blocos ao acaso, com seis repetições e quatro tratamentos correspondentes à reposição de $100 \%$ da água perdida pela evapotranspiração da cultura (T1), a 50\% de reposição (T2), a 25\% de reposição (T3) e sem irrigação (T4). As trocas gasosas foram medidas no estádio fenológico R9, correspondente aos 64 dias após a semeadura (28 dias após o inicio dos tratamentos). A deficiência hídrica foi calculada pelo balanço hídrico diário considerando a capacidade de água disponível (CAD) e a profundidade efetiva do sistema radicular observada em campo. Não houve diferença significativa entre os anos experimentais além do próprio efeito dos tratamentos. O feijão-caupi mostrou-se sensível ao aumento da deficiência hídrica acumulada, diminuindo sua condutância estomática e taxa de fotossíntese, as quais diferiram significativamente entre os 4 tratamentos. Para o potencial hídrico foliar e carbono interno houve diferença significativa apenas entre os tratamentos extremos. Tal comportamento sugere que o feijão-caupi consegue preservar o potencial hídrico foliar mesmo em condições cumulativas de deficiência hídrica agindo como uma espécie conservadora ao priorizar a manutenção de seu status hídrico ao invés da sua atividade fotossintética. As menores produtividades ocorreram em função do déficit hídrico imposto pelos tratamentos com menores lâminas de irrigação.
\end{abstract}

Palavras-chave: Vigna unguiculata (L.) Walp, deficiência hídrica forçada, parâmetros fisiológicos.

\section{Gas Exchange of Cowpea Cultivated in Norteast of Pará in Response to Imposed Water Deficit During Reproductive Phase}

\begin{abstract}
Cowpea (Vigna unguiculata (L.) Walp.) is a cultivated legume in the North and Northeast of Brazil, but in Pará, the crop has low productivity, due to the low soil fertility and climatic adversity, mainly water deficiency. The objective of this work was to evaluate the effect of different levels of cumulative water deficit during reproductive stage on gas exchange of the cowpea. The experiment was conducted in Castanhal / Pa, in the years of 2015 and 2016 in a randomized complete block design, with six replicates and four treatments correpondent to $100 \%$ replacement of the water lost by the evapotranspiration of the crop (T1), to $50 \%$ of replacement (T2), to $25 \%$ of replacement (T3) and without irrigation (T4). Gas Exchange were determined in the phenological stage R9, correspondente to 64 days after sowing (28 dais after the begining of treatments). Water deficit was obtained by daily soil water balance according to the available water
\end{abstract}

Autor de correspondendia: Paulo Jorge de Oliveira Ponte de Souza, paulo.jorge@ufra.edu.br. 
capacity and the size of the effective root system, observed at field. There was not significant difference between experimental years besides the effect of treatments. Cowpea show to be sensitive to the cumulated water déficit, decreasing its stomatal conductance and phtosyntesis rate, which differed significantly among the four treatments. For leaf water potential and internal carbono there was significant difference only between the extreme treatment. Such behavior suggest that cowpea preserve leaf water potential even under cumulative conditions of water deficit acting as a conservative specie by priorizing the maintenance of its water status rather than its photossynthetic activity. The lowest yields occurred in response to the water déficit imposed by the treatments with smaller irrigation blade.

Keywords: Vigna unguiculata (L.) Walp, imposed water déficit, physiological parameters.

\section{Introdução}

O feijão-caupi (Vigna unguiculata (L.) Walp.) é uma leguminosa bastante cultivada por pequenos e médios produtores das regiões Nordeste e Norte do Brasil (Freire Filho et al., 2011), e nos últimos 10 anos por grandes agricultores de outras regiões (Teixeira et al., 2010) sendo uma das principais alternativas sociais e econômicas de suprimento alimentar e geração de emprego, pelo alto valor nutritivo e baixo custo de produção (Oliveira et al., 2011).

Estima-se que o feijão-caupi tenha sido introduzido no estado do Pará por migrantes do Nordeste do Brasil ocupando em média uma área de quase 29.000 ha (Santos e Rebello, 2012). Apesar da importância socioeconômica do feijão-caupi no Estado do Pará, a cultura ainda apresenta baixa produtividade comparada à obtida no Nordeste Brasileiro, variando entre 650 e $850 \mathrm{~kg} \mathrm{ha}^{-1}$ (SEDAP, 2015) resultado de diversos fatores de natureza técnica, comercial, política e principalmente climática (Rebello et al., 2011).

Souza et al. (2017) encontraram produtividades do feijão-caupi para o nordeste do Pará entre 1.115 e $1.396 \mathrm{~kg}$ $\mathrm{ha}^{-1}$ quando cultivados sob baixa deficiência hídrica na fase reprodutiva, mas constaram sua alta sensibilidade à falta d'agua ao obterem produtividades entre 340 e $818 \mathrm{~kg}$ $\mathrm{ha}^{-1}$ na presença de deficiências hídricas acumuladas de 76 e $26 \mathrm{~mm}$, respectivamente. Resultados semelhantes foram encontrados por Freire Filho et al. (2009) para a mesma cultivar BR3-Tracuateua no Nordeste Paraense e por Oliveira et al. (2011) para outra cultivar no estado de Roraima.

A deficiência hídrica interfere na produção das plantas devido inicialmente ao fechamento estomático e redução na absorção de $\mathrm{CO}_{2}$ (Chaves et al., 2002) além de várias alterações metabólicas conforme a intensidade da deficiência hídrica (Ribeiro et al., 2008), chegando a causar a queda das folhas (Santana e Souto, 2011) e redução do crescimento da planta (Bengough et al., 2011).

Apesar do estado do Pará apresentar um regime pluviométrico elevado, as atividades agrícolas ocorrem no primeiro semestre e comumente sob o regime de sequeiro (Freire Filho et al., 2009), o que aumenta o risco climático para esta cultura devido a grande variabilidade sazonal do regime de chuvas (Souza et al., 2016).

Plantas de feijão-caupi submetidas à deficiência hídrica, apresentam reduções na condutância estomática com aumento na resistência difusiva ao vapor de água, mediante o fechamento dos estômatos (Silva et al., 2010). O controle estomático é uma importante propriedade fisiológica por meio da qual as plantas limitam a perda de água, o que reduz a condutância estomática e as trocas gasosas como forma de resposta das plantas ao déficit hídrico (Paiva et al., 2005). De acordo com Taiz e Zeiger (2013) a deficiência hídrica reduz o potencial hídrico das plantas, diminuindo a condutância e a transpiração foliar e como consequência há um aumento da temperatura foliar e redução na produção de fotoassimilados, causando redução no crescimento e na produtividade da cultura (Locatelli et al., 2016).

Poucos estudos foram realizados para a região norte do país sobre o comportamento ecofisiológico do feijãocaupi em resposta à deficiência hídrica cumulativamente forçada, o que poderia auxiliar no ordenamento da cadeia produtiva local e definição de janelas de semeadura mais adequadas para o aumento da produtividade regional. Logo o presente trabalho teve como objetivo avaliar as variáveis ecofisiológicas do feijão-caupi em resposta a deficiência hídrica imposta durante a sua fase reprodutiva.

\section{Material e Métodos}

O experimento foi conduzido no município de Castanhal, localizado na região nordeste do estado do Pará, nos anos de 2015 e 2016 em uma área de aproximadamente 0,5 ha, localizada nas dependências da Fazenda Experimental da Universidade Federal Rural da Amazônia (UFRA) cujas coordenadas geográficas são $1^{\circ} 19^{\prime} 24$ " S latitude, $47^{\circ} 57^{\prime} 38^{\prime \prime}$ W longitude e altitude de $41 \mathrm{~m}$. O clima no local do experimento é definido seguindo classificação climática de Köppen como Am, clima tropical, apresentando moderada estação seca com precipitação pluvial média anual de 2000 a $2500 \mathrm{~mm}$. O período mais seco do ano ocorre entre os meses de junho a novembro, enquanto que de dezembro a maio ocorre o período de maior precipitação.

As características físicas e químicas do solo foram obtidas através análises realizadas no Laboratório de Solos da Embrapa Amazônia Oriental, no município de Belém/ $\mathrm{Pa}$ e apresentados na Tabela 1. O solo da área de estudo foi classificado como Latossolo Amarelo Distrófico Fase Pedregosa I (Concrecionário Laterítico).

A semeadura foi realizada no dia 23 de setembro em 2015, e no dia 17 de setembro em 2016, em ambos os anos 


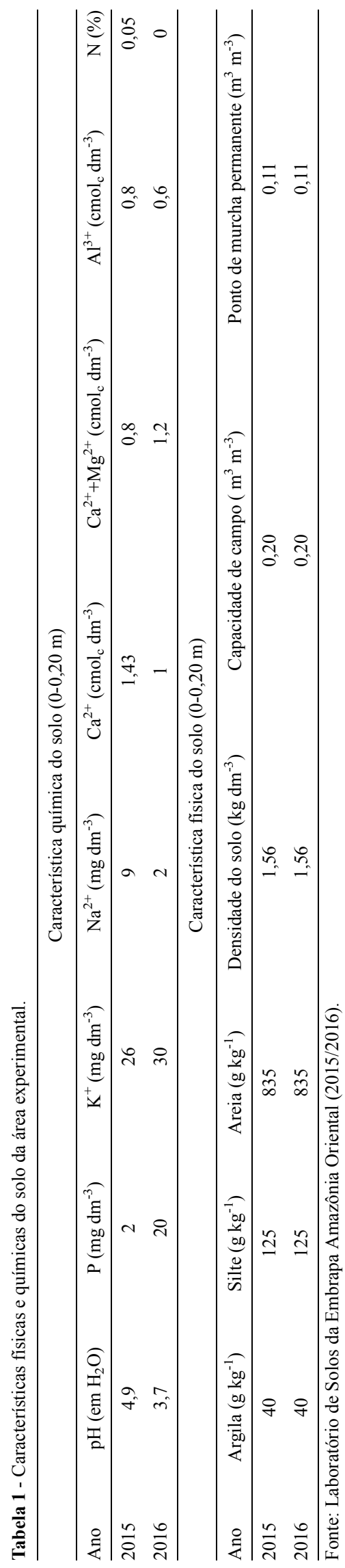

o semeio foi realizado de forma manual, utilizando-se a cultivar BR3-Tracuateua que é a recomendada para a região (Freire Filho et al., 2009). As adubações foram realizadas de acordo com os resultados da análise química do solo, utilizando $350 \mathrm{~kg}$ há $^{-1}$ de fertilizante químico da formulação 10-20-20 (N-P-K) para o experimento de 2015, e $195 \mathrm{~kg} \mathrm{há}^{-1}$ de fertilizante químico da formulação 6-18-15 (N-P-K) em 2016.

O delineamento experimental foi em blocos ao acaso, com seis repetições e quatro tratamentos, com distintos níveis de disponibilidade de água no solo a partir da fase reprodutiva do feijão-caupi. As unidades experimentais consistiram de parcelas medindo $22 \times 24 \mathrm{~m}$, separados por uma bordadura de 1 metro, com espaçamento de $0,5 \mathrm{~m}$ entre linhas de plantio e $0,1 \mathrm{~m}$ entre plantas, perfazendo uma densidade de 200.000 plantas por há.

Os tratamentos consistiram de 4 lâminas diferentes de regime hídrico durante a fase reprodutiva (irrigação + precipitação pluviométrica) representados por T1, 100\% da evapotranspiração da cultura (Etc); T2, 50\% de Etc; T3, $25 \%$ de Etc e T4, sem reposição da Etc. Foram construídas coberturas móveis de polipropileno transparente de 100 microns, com altura de $1,5 \mathrm{~m}$ para os tratamentos $\mathrm{T} 4 \mathrm{de}$ todos os blocos, com o intuito de impedir a entrada de água pela chuva, a partir do estádio reprodutivo, sendo montadas apenas no período de precipitação pluviométrica, durante o dia. Ressalta-se que as coberturas foram utilizadas apenas durante três eventos rápidos de chuva em ambos os anos na fase reprodutiva, e foram retiradas logo após os eventos, não havendo nenhum tipo de efeito nas plantas devido o curto período de uso.

O sistema de irrigação utilizado foi por gotejamento, e para a determinação da lâmina liquida de água utilizou a evapotranspiração de referência $\left(\mathrm{ET}_{0}\right)$ calculada por meio da equação de Penman-Monteith (Allen et al., 2011) com os dados obtidos da estação meteorológica automática do Instituto Nacional de Meteorologia (INMET) instalada à $2 \mathrm{~km}$ do experimento. Em seguida a $\mathrm{ET}_{0}$ foi multiplicada pelo coeficiente de cultura $(\mathrm{Kc})$ de cada fase do feijãocaupi disponível na literatura (Bastos et al., 2008) correspondentes a 0,8 na fase inicial, de 0,8 a 1,1 na fase de desenvolvimento, de 1,1 a 1,4 na fase de estabelecimento e de 1,4 a 0,3 na fase final, a fim de se obter a evapotranspiração máxima da cultura (Etc),

Foi instalada uma estação meteorológica automática no centro da área experimental programada para coletar dados de temperatura do ar, umidade relativa do ar, conteúdo volumétrico de água no solo em cada tratamento e precipitação pluviométrica. Todos os sensores foram conectados a um datalogger CR10X (Campbell Scientific, Inc.), com programação de leitura a cada dez segundos, e médias e totais a cada dez minutos.

Para o cálculo da evapotranspiração real da cultura (Etr) e da deficiência hídrica, adotou-se o método de Thornthwaite e Mather, modificado por Pereira (2005), 
considerando a capacidade de água disponível (CAD) da área experimental $(\approx 35 \mathrm{~mm})$ e a profundidade efetiva do sistema radicular observada visualmente em campo $(\approx 25 \mathrm{~cm})$ (Souza et al., 2017).

$\mathrm{Na}$ fase vegetativa, todos os tratamentos foram mantidos próximos à capacidade de campo (com reposição de $100 \%$ da Etc). A diferenciação das lâminas de água para os tratamentos T2 e T3 e a eliminação da irrigação ao T4, se deram ao $36^{\circ}$ dia após a semeadura para ambos os anos experimentais, correspondente ao inicio da fase reprodutiva. A suspensão da irrigação ocorreu em 2015 ao $58^{\circ}$ e ao $61^{\circ}$ dias após a semeadura (DAS) em 2016, quando a fase de maturação dos grãos (R9) foi atingida. Os estádios fenológicos do feijão-caupi foram determinados após avaliação diária seguindo a escala de desenvolvimento descrita por Farias et al. (2015).

Aos 28 dias após o início dos tratamentos $\left(\approx 64^{\circ}\right.$ DAS, estádio R9) e na presença de deficiência hídrica cumulativa, foram realizadas medidas das taxas de fotossíntese $(A)$, condutância estomática $(g s)$ e concentração interna de $\mathrm{CO}_{2}(\mathrm{Ci})$ com um analisador de gás infravermelho portátil (IRGA), de sistema aberto, modelo 6400XT (LI-COR, Inc.) semelhante ao trabalho de Silva et al. (2017). Foram coletadas duas amostras por tratamento entre 8 e $11 \mathrm{~h}$, no folíolo central da terceira ou quarta folha contadas a partir do ápice, com bom estado fitossanitário e completamente expandidas sob uma intensidade luminosa artificial de $1.500 \mu \mathrm{mol} \mathrm{m} \mathrm{m}^{-2} \mathrm{~s}^{-1}$, concentração de $\mathrm{CO}_{2}$ de $400 \mu \mathrm{mol} \mathrm{mol}^{-1}$, e condições naturais de temperatura e umidade relativa. Determinou-se o potencial hídrico foliar ( $\Psi$ wf) no mesmo horário das trocas gasosas, utilizando-se uma bomba de pressão tipo Scholander modelo 3115 (Soilmoisture Equipment Corp.) nas folhas que foram amostradas com o IRGA.

A produtividade foi medida aos 65 DAS em 2015 e aos 68 DAS em 2016, quando $90 \%$ das plantas atingiram o estádio fenológico R9. Nos dois anos de experimento a produtividade foi determinada em duas linhas de plantio separadas previamente em cada tratamento, de onde foram coletadas três amostras de $1 \mathrm{~m}^{2}$ representadas por linhas de dois metros de comprimento, as quais foram colocadas para secar em estufa a $105^{\circ} \mathrm{C}$ por $72 \mathrm{~h}$, e posteriormente pesados para a estimativa da produtividade em cada tratamento.

Os dados de trocas gasosas foram submetidos à análise de variância pelo teste $\mathrm{F}$ a $5 \%$ de probabilidade, considerando dois fatores de variação (tratamento e ano experimental) e a interação entre ambos. Os dados de produtividade foram submetidos à análise de variância e as médias comparadas pelo teste de Tukey a $5 \%$ de probabilidade, utilizando o programa SAS v. 9.2 (SAS®, North Carolina State University). Realizou-se analise de regressão e as significâncias das equações geradas foram verificadas com base no teste $\mathrm{F}$, considerando-as válidas desde que fossem superiores a $95 \%$ de probabilidade (Silva et al., 2017).

\section{Resultados e Discussão}

O experimento de 2015 sofreu influencia do fenômeno climático do El Niño (Grimm, 2015) com diminuição de chuvas e leve aumento na temperatura do ar durante o ciclo. A temperatura média do ar durante o período experimental de 2015 e 2016 foi de 28,03 e $27,20{ }^{\circ} \mathrm{C}$, respectivamente, como consequência, a evapotranspiração de referência foi maior em $2015(5,03 \mathrm{~mm}$. dia $\left.^{-1}\right)$ do que em $2016\left(4,95 \mathrm{~mm} \cdot \mathrm{dia}^{-1}\right)$. A radiação solar global foi em média 20,56 $\mathrm{MJm}^{-2} \cdot \mathrm{dia}^{-1}$ em 2015 e 19,50 $\mathrm{MJ} \mathrm{m}^{-2} \mathrm{dia}^{-1}$, em 2016, devido menor cobertura de nuvens em 2015 que proporcionou totais de chuva no ciclo de $30,5 \mathrm{~mm}$ em 2015 e de $153,4 \mathrm{~mm}$ em 2016.

A Tabela 2 apresenta as lâminas de água aplicadas antes e após a diferenciação dos tratamentos. Em ambos os anos, a lâmina de água total aplicada em T1 foi suficiente para suprir a demanda hídrica do feijão-caupi $(317,75$ e $354,82 \mathrm{~mm}$, respectivamente), uma vez que o consumo hídrico total para a cultivar e região de estudo é de aproximadamente 267,73 $\pm 10.21 \mathrm{~mm}$ (Farias et al., 2017).

Os dados de umidade do solo, assim como a precipitação do ciclo do feijão-caupi para os anos de 2015 e 2016, são apresentados na Fig. 1. Nota-se que na fase reprodutiva o conteúdo de água no solo variou entre os tratamentos, exibindo um padrão esperado, com o tratamento $\mathrm{T} 1$ apresentando o maior conteúdo volumétrico de água no solo com média de $0,21 \mathrm{~m}^{3} \mathrm{~m}^{-3}$, seguido pelos tratamentos T2 com $0,18 \mathrm{~m}^{3} \mathrm{~m}^{-3}$, T3 com $0,16 \mathrm{~m}^{3} \mathrm{~m}^{-3} \mathrm{e}$ $\mathrm{T} 4$ com $0,14 \mathrm{~m}^{3} \mathrm{~m}^{-3}$, em 2015, enquanto que em 2016 os resultados foram de $0,22 \mathrm{~m}^{3} \mathrm{~m}^{-3}, 0,18 \mathrm{~m}^{3} \mathrm{~m}^{-3}, 0,16 \mathrm{~m}^{3} \mathrm{~m}^{-3}$ e $0,12 \mathrm{~m}^{3} \mathrm{~m}^{-3}$, para $\mathrm{T} 1, \mathrm{~T} 2, \mathrm{~T} 3$ e T4, respectivamente.

Logo que a planta atingiu o estádio R9 houve suspensão da irrigação, quando se verificou que o teor de água disponível em 2015 era de $108 \%, 54 \%, 33 \%$ e $3 \%$ para os tratamentos T1, T2, T3 e T4, respectivamente, correspondendo a deficiências hídricas acumuladas no período de $0 ; 36 ; 58$ e $113 \mathrm{~mm}$, respectivamente. No experimento de 2016, o teor de água disponível para os tratamentos T1, T2, T3 e T4, correspondeu a $122 \%, 47 \%$, $8 \%$ e $0 \%$, associados a deficiências acumuladas de $0 ; 33$; 59 e $95 \mathrm{~mm}$, respectivamente.

No estudo com a cultivar de feijão-caupi IPA 206 sob distintos regimes hídricos no solo, correspondentes ao uso de irrigações quando a agua no solo atingia níveis de 40; 60; 80 e 100\% de água disponível, Nascimento et al. (2004) constataram que as plantas diminuíram de forma significativa sua produção ao nível de $40 \%$ a $60 \%$ de água disponível, ocasionando alterações consideráveis nos componentes de produção, em função da disponibilidade hídrica atribuídas pelos tratamentos.

Não houve diferença significativa do efeito da disponibilidade hídrica entre os anos experimentais para as variáveis ecofisiológicas analisadas, havendo, porém, significância para o efeito individual das lâminas de irrigação 
Tabela 2 - Lâminas aplicadas antes da diferenciação dos tratamentos (Irrigação fase vegetativa e Precipitação fase vegetativa), lâminas aplicadas após a diferenciação dos tratamentos (Irrigação fase Reprodutiva e Precipitação fase Reprodutiva), lâminas totais de água durante o experimento (Total), número de irrigações (NI) e Evapotranspiração da cultura (ETc), para o período experimental dos anos de 2015 e 2016.

\begin{tabular}{|c|c|c|c|c|c|c|c|}
\hline \multirow[t]{3}{*}{ Ano } & \multirow[t]{3}{*}{ Tratamentos } & \multicolumn{6}{|c|}{ Lâmina (mm) } \\
\hline & & \multicolumn{2}{|c|}{ Fase Vegetativa } & \multicolumn{2}{|c|}{ Fase Reprodutiva } & \multirow[t]{2}{*}{ Total } & \multirow[t]{2}{*}{ NI } \\
\hline & & Irrigação & Precipitação & Irrigação & Precipitação & & \\
\hline \multirow[t]{4}{*}{2015} & $\mathrm{~T} 1$ & 173,83 & 0 & 113,45 & 30,47 & 317,75 & 58 \\
\hline & $\mathrm{T} 2$ & 173,83 & 0 & 56,73 & 30,47 & 261,03 & 58 \\
\hline & T3 & 173,83 & 0 & 28,36 & 30,47 & 232,66 & 58 \\
\hline & $\mathrm{T} 4$ & 173,83 & 0 & 0 & 0 & 173,83 & 35 \\
\hline \multirow[t]{4}{*}{2016} & $\mathrm{~T} 1$ & 87,64 & 141,18 & 113,81 & 12,19 & 354,82 & 40 \\
\hline & $\mathrm{T} 2$ & 87,64 & 141,18 & 56,09 & 12,19 & 297,10 & 40 \\
\hline & $\mathrm{T} 3$ & 87,64 & 141,18 & 28,45 & 12,19 & 269,46 & 40 \\
\hline & $\mathrm{T} 4$ & 87,64 & 141,18 & 0 & 0 & 228,82 & 17 \\
\hline
\end{tabular}
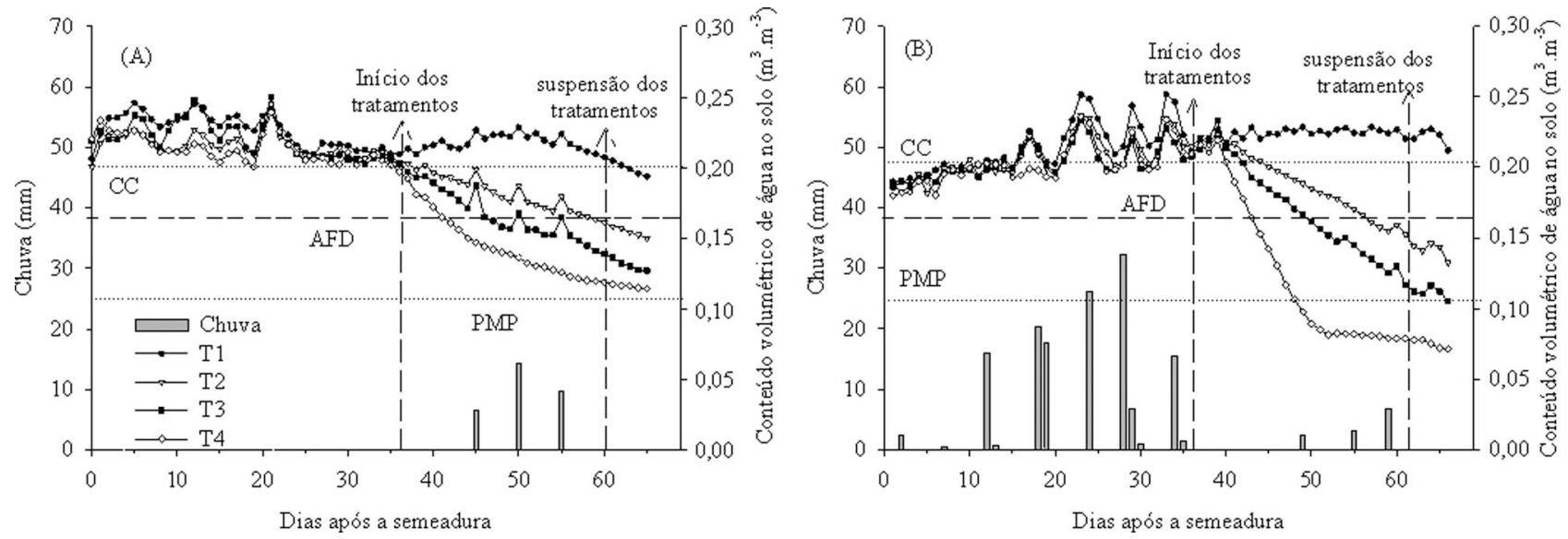

Figura 1 - Umidade do solo para o período experimental nos anos de 2015 (a) e 2016 (b). CC - água na Capacidade de campo, AFD - água facilmente disponível, PMP - Ponto de murcha permanente.

(Tabela 3), com exceção do potencial hídrico foliar que não diferiu entre os tratamentos T2 e T3; e T3 e T4. Silva et al. (2010) também observaram reduções no potencial hídrico foliar e condutância estomática do feijão-caupi em decorrência da deficiência hídrica ocasionando aumento na resistência difusiva ao vapor de água, mediante o fechamento dos estômatos e consequente redução no suprimento de $\mathrm{CO}_{2}$ para a fotossíntese.

A deficiência hídrica imposta pelos tratamentos provocou valores mais negativos de potencial hídrico foliar, alcançando máximos no final do experimento de -1,21 MPa em 2015 e -1,22 MPa em 2016 para o tratamento T4, enquanto que sob ausência de deficiência hídrica observou-se em média -0,63 $\mathrm{MPa}$ para ambos os anos (Fig. 2A). Os demais tratamentos seguiram uma tendência natural para a disponibilidade hídrica do solo, com T2 atingindo valores médios de -1,01 MPa e -1,03 MPa, e T3 com -1,16 MPa e -1,18 MPa, em 2015 e 2016, respectivamente. $\mathrm{O}$ pronto fechamento estomático aos primeiros sinais de déficit hídrico confirma ser um dos principais mecanismos do feijão-caupi para evitar a desidratação, reduzindo a transpiração foliar (Oliveira et al., 2005), com consequente conservação de valores elevados de potencial hídrico (Paiva et al., 2005; Freitas et al., 2017).

Os resultados obtidos se assemelham aos de Souza et al. (2004), que verificaram potencial hídrico foliar de -1,27 MPa sob máximo estresse hídrico e em torno de $-0,71 \mathrm{MPa}$ sob condições sem estresse. Segundo estudo de Nascimento et al. (2011) sobre a tolerância do feijão-caupi ao déficit hídrico, a cultivar BRS-Tracuateua, apresentou potencial hídrico foliar de -1,04 e de -2,05 Mpa em resposta à disponibilidades de água no solo correspondentes a 45 e $75 \%$ de agua disponível no solo.

O tratamento T1 apresentou as maiores taxas de fotossíntese em ambos os anos, atingindo na última observação, média de $32,33 \mu \mathrm{mol} \mathrm{CO}_{2} \mathrm{~m}^{-2} \mathrm{~s}^{-1}$, enquanto que o tratamento T4 chegou apenas a $8,03 \mu \mathrm{mol} \mathrm{CO} \mathrm{Cm}^{-2} \mathrm{~s}^{-1}$ ao final do ciclo, em resposta a uma deficiência total de aproximadamente $100 \mathrm{~mm}$. A redução observada na taxa fotossintética ajustou-se a um padrão linear (Fig. 2B). Observou- 
Tabela 3 - Resumo da análise de variância e médias do potencial hídrico foliar, Taxa de Fotossíntese, condutância estomática e concentração interna de carbono do feijão-caupi em função da disponibilidade hídrica e do ano experimental (2015 e 2016).

\begin{tabular}{|c|c|c|c|c|c|}
\hline \multirow[t]{2}{*}{ FV } & \multirow[t]{2}{*}{ GL } & \multicolumn{4}{|c|}{ QM } \\
\hline & & $\Psi_{\mathrm{wf}}(\mathrm{Mpa})$ & $\mathrm{A}\left(\mathrm{mmol} \mathrm{CO} \mathrm{C}_{2} \cdot \mathrm{m}^{-2} \cdot \mathrm{s}^{-1}\right)$ & $\mathrm{g}_{\mathrm{s}}\left(\mathrm{mmol} \mathrm{H} \mathrm{H}_{2} \mathrm{O} \cdot \mathrm{m}^{-2} \cdot \mathrm{s}^{-1}\right)$ & $\mathrm{C}_{\mathrm{i}}\left(\mu \mathrm{mol} \mathrm{mol} \mathrm{mo}^{-1}\right)$ \\
\hline Tratamento & 3 & $0,836^{* *}$ & $1336,364^{* *}$ & $547106,12^{* *}$ & $8853,95^{* *}$ \\
\hline Experimento & 1 & $0,0064^{\mathrm{ns}}$ & $1,0732^{\mathrm{ns}}$ & $637,724^{\mathrm{ns}}$ & $110,445^{\mathrm{ns}}$ \\
\hline Interação & 3 & $0,0004^{* *}$ & $6,584^{\mathrm{ns}}$ & $209,859^{*}$ & $81,027^{\mathrm{ns}}$ \\
\hline Bloco & 5 & $0,15^{* *}$ & $1,768^{\text {ns }}$ & $4528,81^{\mathrm{ns}}$ & $160,85^{\mathrm{ns}}$ \\
\hline Resíduo & 35 & 0,026 & 2,51 & 3049,222 & 94,554 \\
\hline $\mathrm{CV} \%$ & - & 15,95 & 8,10 & 18,75 & 4,19 \\
\hline Lâmina & & \multicolumn{4}{|c|}{ Média $^{1}$} \\
\hline $\mathrm{T} 1$ & & $-0,6342^{\mathrm{a}}$ & $32,33^{\mathrm{a}}$ & $548,843^{\mathrm{a}}$ & $262,012^{\mathrm{a}}$ \\
\hline $\mathrm{T} 2$ & & $-1,018^{\mathrm{b}}$ & $23,26^{\mathrm{b}}$ & $387,408^{\mathrm{b}}$ & $247,654^{\mathrm{b}}$ \\
\hline $\mathrm{T} 3$ & & $-1,168^{\mathrm{bc}}$ & $14,61^{\mathrm{c}}$ & $161,024^{\mathrm{c}}$ & $210,693^{\mathrm{c}}$ \\
\hline $\mathrm{T} 4$ & & $-1,2171^{\mathrm{c}}$ & $8,031^{\mathrm{d}}$ & $80,868^{\mathrm{d}}$ & $207,226^{\mathrm{c}}$ \\
\hline
\end{tabular}

se no final da fase reprodutiva uma redução de 24,53 e $76 \%$ para os tratamentos T2, T3 e T4, no experimento de 2015, e para 2016 cerca de 32, 57 e de $74 \%$ para T2, T3 e T4, em comparação ao tratamento $\mathrm{T} 1$, respectivamente.

Essa resposta linear de decréscimo da taxa fotossintética à falta d'água foi também observada por Silva et al. (2017) e ocorre possivelmente devido á diminuição da condutância estomática ( $g s)$, uma vez que a abertura estomática é a principal responsável pela entrada e saída de gases na planta (Kerbauy, 2009) regulando as trocas gasosas e controlando o processo fotossintético (Paiva et al., 2005). A redução na área foliar das plantas em função da deficiência hídrica limita a atividade fotossintética em virtude da queda tanto na interceptação de luz e consequentemente na absorção de $\mathrm{CO}_{2}$ (Mattos et al., 2005).
A condutância estomática $(g s)$ também respondeu linearmente à deficiência hídrica (Fig. 3A) semelhante ao observado por Silva et al. (2017), ajustando-se a uma função linear $(\mathrm{p}<0,01)$. Ao final do ciclo o feijão-caupi apresentou condutância média de $80,87 \mathrm{mmol} \mathrm{H}_{2} \mathrm{O} \mathrm{m}^{-2} \mathrm{~s}^{-1}$ para o tratamento T4. Para o tratamento T2 o feijão-caupi apresentou condutância de $387,4 \mathrm{mmol} \mathrm{H}_{2} \mathrm{O} \mathrm{m}^{-2} \mathrm{~s}^{-1}$ e para $\mathrm{T} 3,161 \mathrm{mmol} \mathrm{H}_{2} \mathrm{O} \mathrm{m}^{-2} \mathrm{~s}^{-1}$, os quais comparados ao tratamento sem deficiência representam uma redução média de $30 \%$ para o T2, de $71 \%$ para T3 e de $86 \%$ para o T4.

A redução da condutância estomática é explicada por Kerbauy (2009) que relata, que quando a planta se encontra em estresse hídrico, tende a fechar seus estômatos para reduzir a perda de água preservando um certo turgor (maior potencial de água) em algumas espécies, uma
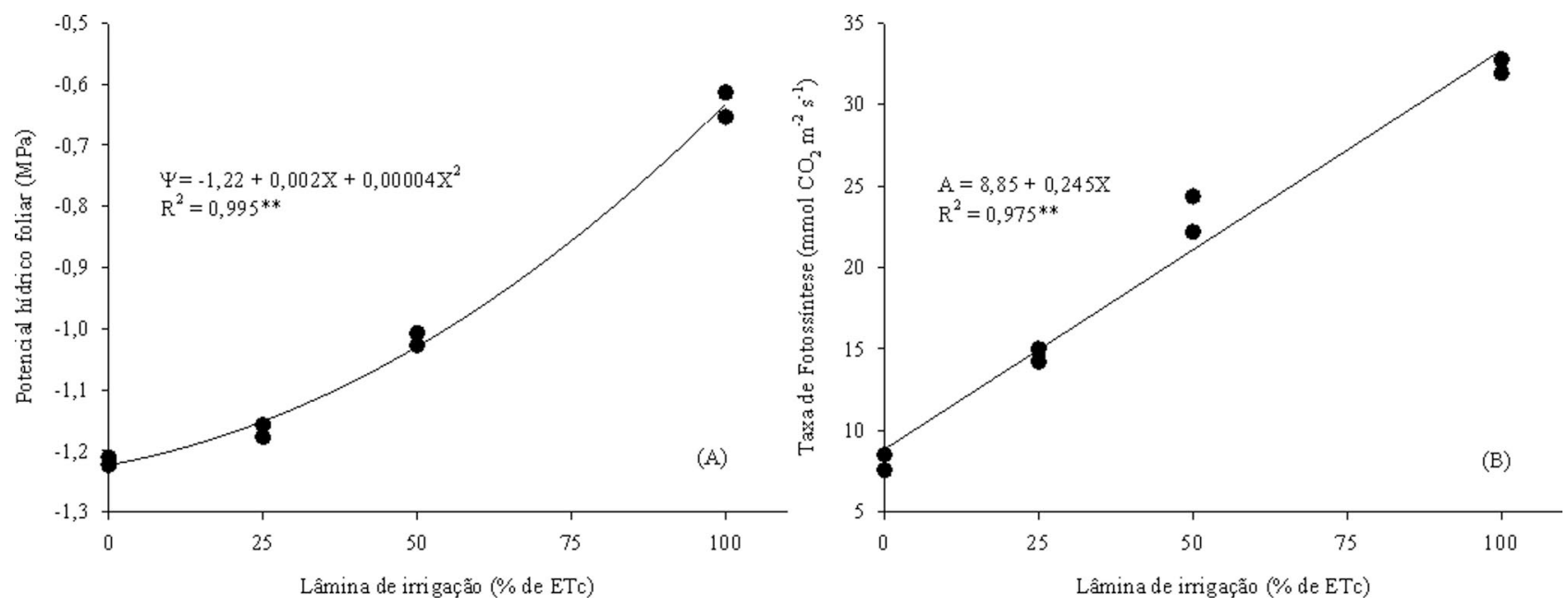

Figura 2 - Potencial hídrico foliar (A) e Taxa de fotossíntese (B) no feijão-caupi submetido à distintas disponibilidades de água. ** - significativo pelo teste $\mathrm{F}(\mathrm{p}<0,01)$. 

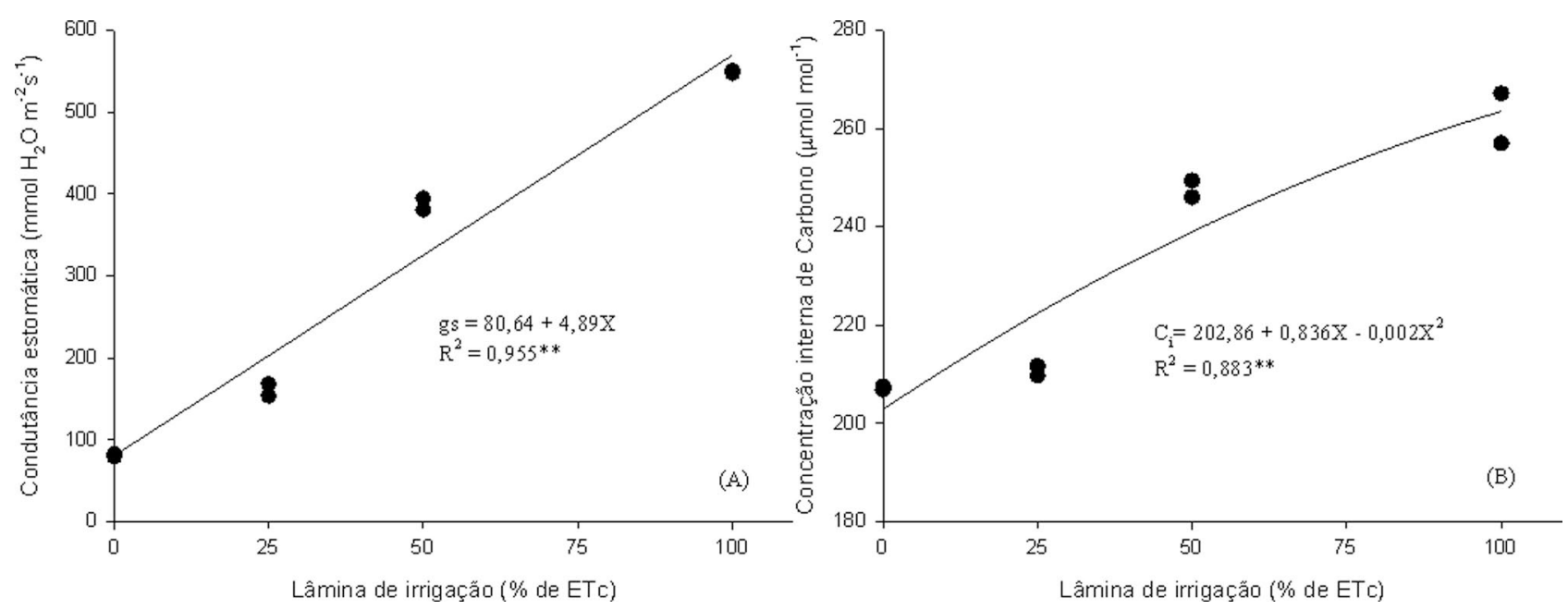

Figura 3 - Condutância estomática (A) e Concentração interna de carbono (B) no feijão-caupi submetido a distintas disponibilidades de água. ** - significativo pelo teste $\mathrm{F}(\mathrm{p}<0,01)$.

importante característica de tolerância à seca (Mendes et al., 2007).

Em ambos os experimentos a concentração interna de $\mathrm{CO}_{2}(\mathrm{C} i)$ respondeu negativamente ao aumento da deficiência hídrica (Fig. 3B) ajustando-se a um modelo polinomial de segunda ordem $(\mathrm{p}<0,01)$, semelhante ao observado por Silva et al. (2017), apresentando uma redução média de $21 \%$ ao sair de uma condição sem deficiência hídrica para a condição média de $103 \mathrm{~mm}$ de deficiência hídrica acumulada. Quanto maior a falta de água na planta, menor será o grau de abertura dos ostíolos e, consequentemente, maior a resistência à entrada do $\mathrm{CO}_{2}$ atmosférico, fazendo com que as concentrações intrafoliares de $\mathrm{CO}_{2}$ diminuam significativamente (Taiz e Zeiger, 2013).

A concentração interna média de $\mathrm{CO}_{2}$ observada no feijão-caupi foi de $207 \mu \mathrm{mol} \mathrm{mol}^{-1}$ para T4, $210 \mu \mathrm{mol} \mathrm{mol}^{-1}$ para T3, $247 \mu \mathrm{mol} \mathrm{mol}^{-1}$ para T2 e $262 \mu \mathrm{mol} \mathrm{mol}^{-1}$, para $\mathrm{T} 1$, correspondendo a um aumento significativo de $26,6 \%$ do tratamento sem irrigação para o $100 \%$ irrigado (Tabela 3). O aumento nos valores de $\mathrm{Ci}$ seguiu os acréscimos na $g s$ em resposta à maior disponibilidade hídrica, pois quanto maior a abertura estomática maior será a difusão de $\mathrm{CO}_{2}$ para a câmara subestomática (Nascimento et al., 2011). Sob tais condições há o aumento da atividade da enzima rubisco e consequentemente o aumento do consumo de $\mathrm{CO}_{2}$ (Machado et al., 2005).

Por outro lado, quando plantas são submetidas ao estresse hídrico, verifica-se uma redução na abertura estomática como medida de proteção, e consequentemente redução no influxo de $\mathrm{CO}_{2}$ na câmara subestomática (Silva et al., 2017). Taiz e Zeiger (2013) relatam que quando a água do solo é menos abundante, os estômatos reduzem sua abertura, ou até mesmo permanecem fechados mesmo na presença da luz, como estratégia para evitar a desidratação através da transpiração, mantendo às vezes altos valores de potencial hídrico foliar (Kerbauy, 2009).
Os resultados da analise de variância (Tabela 3) corroboram esta teoria ao se constatar que mesmo com a redução significativa nas variáveis analisadas entre os tratamentos, em especial entre os tratamentos T1 e T4, o potencial hídrico foliar não diferenciou significativamente entre os tratamentos T2 e T3, e T3 e T4, demonstrando que o feijão-caupi consegue preservar o potencial hídrico foliar mesmo em condições cumulativas de deficiência hídrica. Esta característica foi também observada por Guimarães et al. (2006) para o feijão comum e por Freitas et al. (2017) ao constatar que o feijão-caupi age como uma espécie conservadora ao priorizar a manutenção de seu status hídrico ao invés da sua atividade fotossintética.

A produtividade de grãos do feijão-caupi em ambos os anos, comprovou que as distintas disponibilidades hídricas no solo influenciaram diretamente na produção, pois quanto maior as deficiências impostas pelos tratamentos, menores foram os valores do peso final grão (Fig. 4). A média de produtividade dos tratamentos de 2015 foi de $1.474 \mathrm{~kg} \mathrm{ha}^{-1}$ (T1), $1.098 \mathrm{~kg} \mathrm{ha}^{-1}$ (T2), $943 \mathrm{~kg}$ $\mathrm{ha}^{-1}$ (T3), e $638 \mathrm{~kg} \mathrm{ha}^{-1}$ (T4), enquanto que em 2016 foi de $1.597 \mathrm{~kg} \mathrm{ha}^{-1}$ (T1), $1.295 \mathrm{~kg} \mathrm{ha}^{-1}$ (T2), $1.069 \mathrm{~kg} \mathrm{ha}^{-1}$ (T3), e $684 \mathrm{~kg} \mathrm{ha}^{-1}$ (T4). As deficiências médias dos dois experimentos impostas pelos tratamentos T2, T3 e T4, causaram uma redução média de ambos os anos de 22,2; 34,6 e de $56,9 \%$ na produtividade final, respectivamente.

Souza et al. (2017) submeteram a mesma cultivar a condição irrigada por todo o período e condição não irrigada na fase reprodutiva em experimentos realizados em 2012 e 2013 e obtiveram produtividades médias de 1.258 e de $1.396 \mathrm{~kg} \mathrm{ha}^{-1}$ no tratamento irrigado, e de $340 \mathrm{e}$ $818 \mathrm{~kg} \mathrm{ha}^{-1}$ para o tratamento não irrigado, respectivamente. Tais resultados corroboram o fato de que na ausência de deficiência hídrica o feijão-caupi pode atingir produtividades superiores à média estadual (entre 650 e $850 \mathrm{~kg} \mathrm{ha}^{-1}$ ), mas que em decorrência de deficiências 


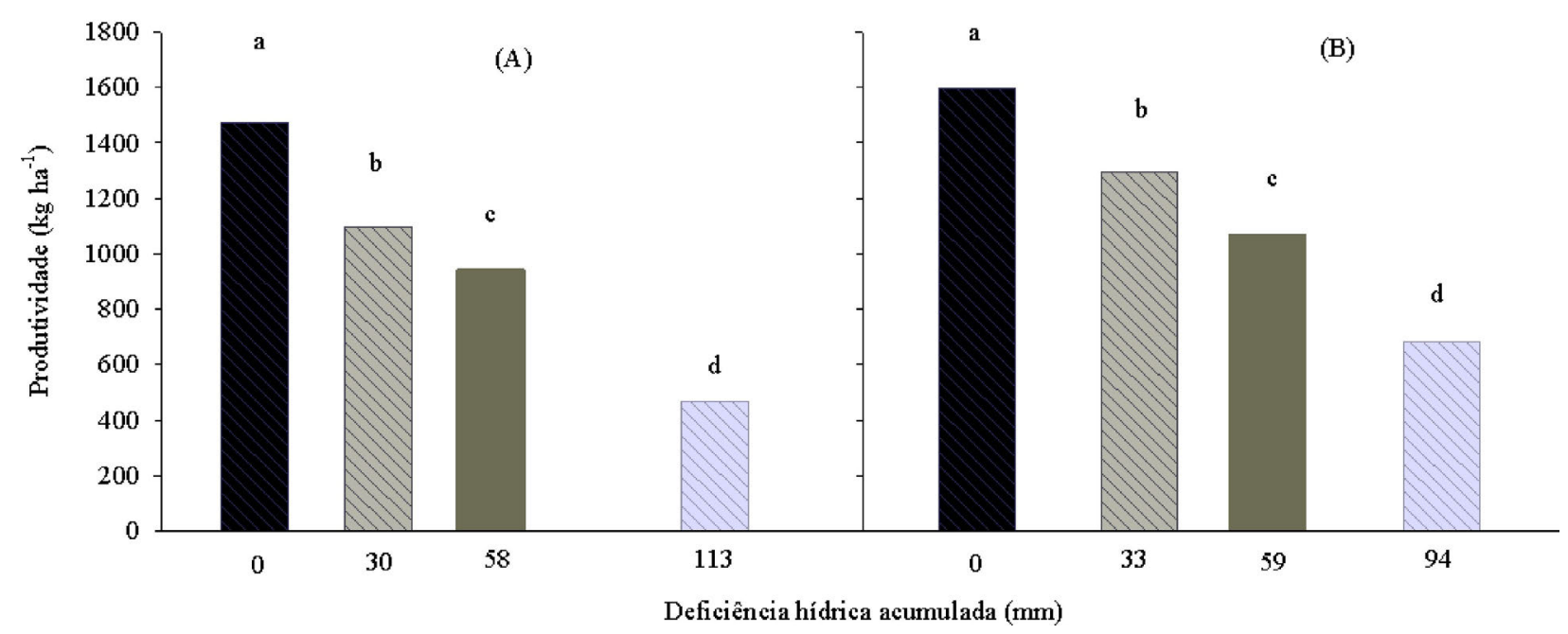

Figura 4 - Produtividade do feijão-caupi em 2015 (A) e em 2016 (B) submetido a deficiência hídrica acumulada, Castanhal-Pa. Letras diferentes indicam diferença significativa de acordo com o teste de Tukey $(p<0,05)$.

hídricas na fase reprodutiva, de distintas magnitudes destas deficiências, e de qual período dentro da fase elas ocorrem, é possível se obter reduções na produtividade que variam de 41 a $72 \%$.

Segundo Paiva et al. (2005) a gs por ter função de regular as trocas gasosas, possui grande afinidade com o processo fotossintético, participando diretamente no crescimento e desenvolvimento das plantas e na presença de déficit hídrico proporciona redução na produção de fotoassimilados, causando redução nos componentes de produção e na produtividade final (Taiz e Zeiger, 2013).

Segundo Silva et al. (2010) a deficiência hídrica inviabiliza nas plantas diversos processos fisiológicos e metabólicos, ocasionando diminuição da produtividade, haja vista, que a água é um dos principais responsáveis pela regulação dos estômatos. Tal comportamento pode ser explicado como um dos mecanismos de resistência à seca utilizado por esta cultivar, no sentido de buscar melhores condições para superar a falta de água, produzindo menor quantidade de vagens e grãos por vagem (Ramos et al., 2014; Dutra et al., 2015).

\section{Conclusão}

$\mathrm{O}$ acumulo de deficiência hídrica na fase reprodutiva diminui significativamente as trocas gasosas da cultivar BR3-Tracuateua, em especial sua condutância estomática e taxa de fotossíntese. O potencial hídrico foliar e o carbono interno do feijão-caupi cultivar BR3-Tracuateua só diferem significativamente na presença de elevada deficiência hídrica acumulada. O feijão-caupi cultivar BR3Tracuateua se comporta como uma espécie conservadora priorizando a manutenção de seu status hídrico ao invés da sua atividade fotossintética. Considerando as condições experimentais e a cultivar adotada, recomenda-se o uso da lâmina de 50\% (DEF de $30-33 \mathrm{~mm}$ ) para o cultivo do feijão-caupi, pois, embora tenha diferido estatisticamente da lâmina de $100 \%$, a diferença média é de apenas $340 \mathrm{~kg} \mathrm{ha}^{-1}$, e o rendimento obtido é superior a média estadual.

\section{Agradecimentos}

Ao Conselho Nacional de Desenvolvimento Cientifico e Tecnológico ( $\mathrm{CNPq}$ ) pelo financiamento da pesquisa através do projeto Universal (processo $\mathrm{n}^{\circ} 483402 / 2012-5$ ) e pela bolsa de produtividade em pesquisa do primeiro autor (processo $n^{\circ} 311145 / 2013-2$ ), ao prof. Dr. Hugo Pinheiro da UFRA pela disponibilização do IRGA e da bomba de Scholander.

\section{Referências}

ALLEN, R.G.; PEREIRA, L.S.; HOWELL, T.A.; JENSES, M.E. Evapotranspiration information reporting: I. Factors governing measurement accuracy. Agricultural Water Management, v. 98, n. 6, p. 899-920, 2011.

BASTOS, E.A.; FERREIRA, V.; SILVA, C.; ANDRADE JUNIOR, A. Evapotranspiração e coeficiente de cultivo do feijão-caupi no vale do Gurguéia, PI. Irriga, v. 13, n. 2, p. 182-190, 2008.

BENGOUGH, A.G.; McKENZIE, B.M.; HALlETT, P.D.; VALENTINE, T.A. Root elongation, water stress, and mechanical impedance: a review of limiting stresses and beneficial root tip traits. Journal of Experimental Botany, v. 62, n. 1, p. 59-68, 2011.

CHAVES, M.M.; PEREIRA, J.S.; MAROCO, J.; RODRIGUES, M.L.; RICARDO, C.P. et al. How plants cope with water stress in the field. Photosynthesis and growth. Annals of Botany, v. 89, n. 7, p. 907-916, 2002.

DUTRA, A.F.; MELO, A.S.; FILGUEIRAS, L.M.B.; SILVA, A.R.F.; OLIVEIRA, I.M. et al. Parâmetros fisiológicos e 
componentes de produção de feijão-caupi cultivado sob deficiência hídrica Revista Brasileira de Agricultura Irrigada, v. 10, n. 2, p. 189-197, 2015.

FARIAS, V.D.S.; COSTA, D.L.P.; SOUZA, P.J.O.P.; TAKAKI, A.Y.; LIMA, M.J.A. Temperaturas basais e necessidade térmica para o ciclo de desenvolvimento do feijão-caupi. Enciclopédia Biosfera, v. 11, n. 21, p. 1781-1792, 2015.

FARIAS, V.D.S. LIMA, M.J.A.; NUNES, H.G.G.C.; SOUSA, D.P.; SOUZA, P.J.O.P. Water demand, crop coefficient and uncoupling factor of cowpea in the eastern amazon. Caatinga, v. 30, n. 1, p. 190-200, 2017.

FREIRE FILHO. F.R.; CRAVO, M.S.; RIBEIRO, V.Q.; ROCHA, M.M.; CASTELO, E.O. et al. BRS Milênio e BRS Urubuquara: cultivares de feijão-caupi para a região Bragantina do Pará. Revista Ceres, v. 56, n. 6, p. 749-752, 2009.

FREIRE FILHO, F.R.; RIBEIRO, V.Q.; ROCHA, M.M.; SILVA, K.J.D.; NOGUEIRA, M.S.R. et al. Feijão-caupi no Brasil: Produção, melhoramento genético, avanços e desafios. 1.ed. Teresina: Embrapa Meio-Norte, 2011, 84 p.

FREITAS, R.M.O.; DOMBROSKI, J.L.D.; FREITAS, F.C.L.; NOGUEIRA, N.W.; PINTO, J.R.S. Physiological responses of cowpea under water stress and rewatering in no-tillage and conventional tillage systems. Caatinga, v. 30, n. 3, p. 559-567, 2017.

GRIMM, A.M. El niño, novamente! Revista Brasileira de Meteorologia, v. 30, n. 4, 351-357, 2015.

GUIMARÃES, C.M.; STONE, L.F.; BRUNINI, O. Adaptação do feijoeiro comum (Phaseolus vulgaris L.) à seca. Revista Brasileira de Engenharia Agrícola e Ambiental, v. 10, n. 1, p. 70-75, 2006.

KERBAUY, G.B. Fisiologia Vegetal. Rio de Janeiro: Guanabara Koogan, 452 p. 2009.

LOCATELLI, V.E.R.; MEDEIROS, R.D.; SMIDERLE O.J.; ALBUQUERQUE, J.A.A.; ARAÚJO, W.F. Desenvolvimento vegetativo de cultivares de feijão-caupi sob lâminas de irrigação no cerrado roraimense. Irriga, v. 1, n. 1, p.2839, 2016.

MACHADO, E.C.; SCHMIDT, P.T.; MEDINA, C.L.; RIBEIRO, R.V. Respostas da fotossíntese de três espécies de citros a fatores ambientes. Pesquisa Agropecuária Brasileira, v. 40, n. 12, p. 1161-1170, 2005.

MATTOS, J.L.S.; GOMIDE, J.A.; MARTINEZ Y HUAMAN, C.A. Crescimento de espécies do gênero Brachiaria, sob déficit hídrico, em casa de vegetação. Revista Brasileira de Zootecnia, v. 34, n. 3, p. 746-754, 2005.

MENDES, R.M.S.; TAVORA, F.J.A.F.; PITOMBEIRA, J.B.; NOGUEIRA, R.J.M.C. Relações fonte-dreno em feijão-decorda submetido à deficiência hídrica. Revista Ciência Agronômica, v.38, n. 1, p. 95-103, 2007.

NASCIMENTO, J.T.; PEDROSA, M.B.; TAVARES, S.J. Efeito da variação de níveis de água disponível no solo sobre o crescimento e produção de feijão caupi, vagens e grãos verdes. Horticultura Brasileira, v. 22, n. 2, p. 174-177, 2004.

NASCIMENTO, S.P.; BASTOS, E.A.; ARAUJO, E.C.E.; FREIRE FILHO, F.R.; SILVA, E.M. Tolerância ao déficit hídrico em genótipos de feijão-caupi. Revista Brasileira de Engenharia Agrícola e Ambiental, v. 15, n. 8, p. 853860, 2011.

OLIVEIRA, G.A.; ARAUJO, W.F.; CRUZ, P.L.S.; LIMA, W.L.M.; FERREIRA, G.B. Resposta do feijão-caupi as lâminas de irrigação e as doses de fósforo no cerrado de Roraima. Revista Ciência Agronômica, v. 42, n. 4, p. 872882, 2011

PAIVA, A.S.; FERNANDES, E.J., RODRIGUES, T.J.D.; TURCO, J.E.P. Condutância estomática em folhas de feijoeiro submetido a diferentes regimes de irrigação. Engenharia Agrícola, v. 25, n. 1, p. 161-169, 2005.

PEREIRA, A.R. Simplificando o balanço hídrico de Thornthwaite e Mather. Bragantia, v. 64, n. 2, p. 311-313, 2005.

RAMOS, H.M.M.; BASTOS, E.A.; CARDOSO, M.J.; RIBEIRO, V.Q.; NASCIMENTO, F.N. Produtividade de grãos verdes do feijão-caupi sob diferentes regimes hídricos. Engenharia Agrícola, v. 34, n. 4, p. 683-694, 2014.

REBELlO, F.K.; COSTA, A.J.G.; FIGUEIRO, C.L.M. Conjuntura da produção e comercialização do feijão caupi no Nordeste Paraense: safra 2010. Contexto Amazônico, v. 4, n. 18, p. 1-4, 2011.

RIBEIRO, R.V.; SANTOS, M.G.; MACHADO, E.C.; OLIVEIRA, R.F. Photochemical heat-shock response in common bean leaves as affected by previous water deficit. Russian Journal of Plant Physiology, v. 55, n. 3, p. 350358, 2008

SANTANA, J.A.S.; SOUTO, J.S. Produção de serapilheira na Caatinga da região semi- árida do Rio Grande do Norte, Brasil. IDESIA, v. 29, n. 2, p. 87-94, 2011.

SANTOS, M.A.S.; REBELLO, F.K. Perfil socioeconômico e tecnológico dos pequenos produtores de feijão-caupi do município de Primavera, Nordeste do Pará - Brasil. Revista Verde de Agroecologia e Desenvolvimento Sustentável, v. 7, n. 5, p. 72-82, 2012.

SEDAP. Secretaria de Estado de Desenvolvimento Agropecuário e da pesca, 2015. Dados Agropecuários. Disponível em: $<$ http://www.sedap.pa.gov.br/>. Acesso em: 10 de Junho de 2017.

SILVA, C.D.S.; SANTOS, P.A.A.; LIRA, J.M.S.; SANTANA, M.C.; SILVA JUNIOR, C.D. Curso diário das trocas gasosas em plantas de feijão-caupi submetidas a deficiência hídrica, Caatinga, v. 23, n. 4, p. 7-13, 2010.

SILVA, W.C.; MOURA, J.G.; OLIVEIRA, A.B.; FERREIRA, L.E.; SILVA, T.M. Growth and gas exchange in cowpea plants under different managements and saline conditions. Revista Ciência Agronômica, v. 48, n. 5, p. 756-764, 2017.

SOUZA, R. P.; MACHADO, E.C.; SILVA, J.A.B.; LAGOA, A.M.M.A.; SILVEIRA, J.A.G. Photoshynthetic gás Exchange, chorophyll fluorescence and some associated metabolic changes in cowpea (Vigna unguiculata) during water stress and recovery. Enviromental and Experimental Botany, v. 51, n. 1, p. 45-56, 2004.

SOUZA, E.B.; CARMO, A.M.C.; MORAES, B.C.; NACIF, A.; FERREIRA, D.B.S. et al. Sazonalidade da precipitação sobre a Amazônia legal Brasileira: clima atual e projeções 
futuras usando o modelo REGCM4. Revista Brasileira de Climatologia, v. 18, n.1, p. 293-306, 2016.

SOUZA, P.J.O.P.; FARIAS, V.D.S.; LIMA, M.J.A.; RAMOS, T.F.; SOUSA, A.M.L. Cowpea leaf area, biomass production and productivity under different water regimes in Castanhal, Pará, Brazil. Caatinga, v. 30, n. 3, p. 748-759, 2017.

TAIZ, L.; ZEIGER, E. Fisiologia Vegetal. 3. ed. Porto Alegre: Artmed, 2013.
TEIXEIRA, I.R.; SILVA, G.C.; RIBEIRA-OLIVEIRA, J.P.; SILVA, A.G.; PELÁ, A. Desempenho agronômico e qualidade de sementes de cultivares de feijão-caupi na região do cerrado. Revista Ciência Agronômica, v. 41, n. 2 , p. 300$307,2010$.

License information: This is an open-access article distributed under the terms of the Creative Commons Attribution License (type CC-BY), which permits unrestricted use, distribution and reproduction in any medium, provided the original article is properly cited. 